\title{
Gold Nanostar Assays for Oncology and Virology
}

\author{
Manjari Bhamidipati ${ }^{1}$, Kholud Dardir ${ }^{1}$, Hao Wang ${ }^{l}$ and Laura Fabris ${ }^{1, *}$
}

\footnotetext{
${ }^{1)}$ Rutgers university, Piscataway, United States

${ }^{*}$ E-mail lfabris@, soe.rutgers.edu
}

Plasmonic nanostructures are well-known as effective substrates for applications in which near field enhancements are sought. In particular, we have shown that gold nanoparticles can be employed to carry out identification of U87 glioblastoma cells with surface enhanced Raman spectroscopy (SERS), by targeting overexpressed $\alpha \mathrm{V} \beta 3$ integrins via RGD peptides [1]. However, gold nanostars have been shown to lead to much higher field enhancements, owing to their uniquely sharp protruding spikes. In particular, we have shown how they can be employed to build sensing platforms for the direct identification of small molecule analytes by SERS achieving femtomolar limits of detection [2]. We have also demonstrated how gold nanostars can be tethered to rigid substrates and conjugated in situ to aptamers for targeting and recognition of prostate cancer cells and enable the quantification of cancer cell biomarkers at the single cell level [3]. In this talk I will also present how SERS-based quantification of prostate specific membrane antigen (PSMA), a promising biomarker for prostate cancer diagnosis, enables discrete patient stratification, and how gold nanostars can be uniquely employed for the identification of influenza virus mutations at the single cell level with no interference from protein corona.
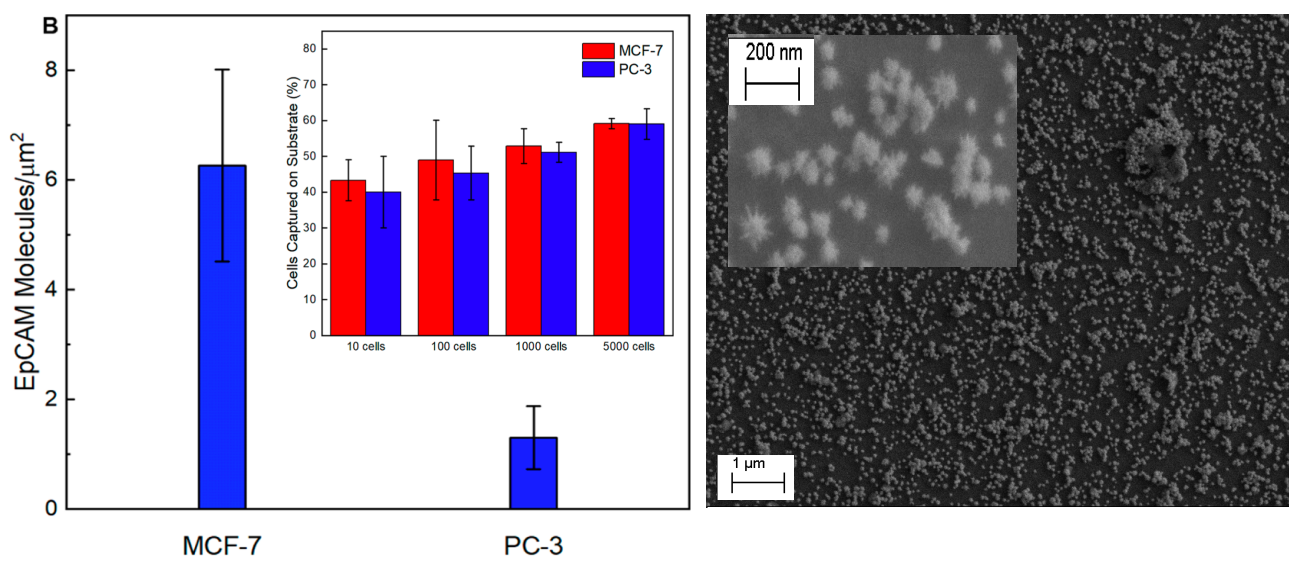

Figure 1. Gold nanostar substrates functionalized with EpCAM-specific aptamers enable to achieve 50\% yield in cell capture and quantification of the biomarker at the single cell level.

\section{References.}

[1] Indrasekara, A. S. D. S.; Paladini, B. J.; Naczynski, D. J.; Starovoytov, V.; Moghe, P. V.; Fabris, L. Adv. Healthcare Mater. 2013, 2, 1370.

[2] Indrasekara, A. S. D.S.; Meyers, S.; Shubeita, S.; Feldman, L. C.; Gustafsson, T.; Fabris, L. Nanoscale 2014, 6, 8891.

[3] Bhamidipati, M.; Cho, H. Y.; Lee, K.-B.; Fabris, L. Bioconj. Chem. 2018, 29, 2970. 